\title{
Hipertexto: evolução histórica e efeitos sociais
}

\section{Cláudia Augusto Dias}

\section{Resumo}

Nesta exposição cronológica, são abordados os avanços na comunicação da informação, passando por diferentes estágios culturais e tecnológicos - a escrita, a imprensa e a tecnologia da informação. O propósito deste artigo é destacar, em especial, os avanços tecnológicos que propiciaram a origem dos hipertextos e os efeitos sociais dessa nova tecnologia.

O hipertexto se insere no contexto da cibercultura, como uma de suas novas interfaces de comunicação. Na verdade, o hipertexto resgata e modifica antigas interfaces da escrita, como a segmentação em módulos (capítulos e seções), o acesso seletivo e não-linear ao texto (índices e sumários), as conexões a outros documentos (notas de rodapé e referências bibliográficas), implementadas com novas tecnologias. Essa nova maneira de escrever pode ser usada para organizar e divulgar os conhecimentos sobre uma determinada área do saber, sendo especialmente útil nas áreas de gestão de informações, comunicação e educação.

\section{Palavras-chave}

Hipertexto; Hipermídia.

\section{INTRODUÇÃO}

Nesta exposição cronológica, são abordados os avanços na comunicação da informação a partir da revolução da escrita, quando o homem passa da comunicação oral e interativa direta das culturas tribais para a comunicação escrita, baseada em textos lineares e no uso de alfabetos. A escrita trouxe uma nova perspectiva para a comunicação, já que, nas sociedades orais, seus participantes (emissor e receptor de mensagens) partilhavam do mesmo contexto, isto é, a comunicação ocorria, por meio da linguagem, no mesmo tempo e espaço em que ambos se encontravam. A comunicação baseava-se nas lembranças das pessoas; em especial, em sua memória auditiva. Os membros das sociedades sem escrita exploravam ao máximo artifícios, como dramatizações, rituais, danças e músicas, como forma de transmitir e perpetuar acontecimentos e histórias que consideravam relevantes. Não havia, entretanto, qualquer garantia de que a mensagem oral seria a mesma após

\section{FIGURA 1}

\section{As diferentes fases da comunicação da informação²}

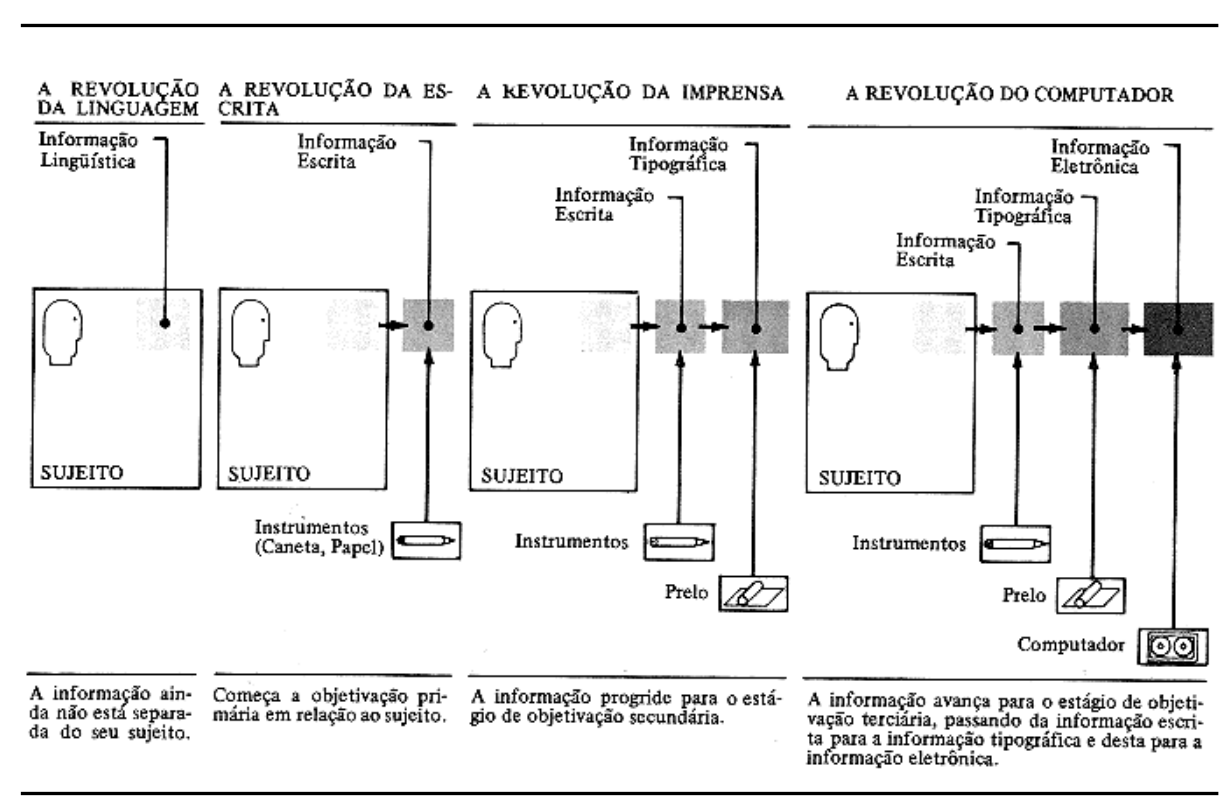

vários estágios de transmissão.

Com a escrita, passou a ser possível tomar conhecimento de fatos presenciados ou relatos feitos por pessoas que viveram em outras épocas ou lugares. Pela primeira vez na história da humanidade, o discurso pôde ser compreendido e analisado fora do contexto em que foi produzido. Segundo Lévy, "a comunicação puramente escrita elimina a mediação humana no contexto que adaptava ou traduzia as mensagens vindas de um outro tempo ou lugar"1.

Milhares de anos depois, o homem se deparou com outras duas revoluções: a revolução da imprensa e a revolução do computador ${ }^{2}$. Para Barreto, "esta passagem da cultura tribal para a cultura escrita/tipográfica foi uma transformação tão profunda para o indivíduo e para a sociedade, como está sendo a passagem da cultura escrita para a cultura eletrônica, que ora presenciamos"3. 
O propósito deste artigo é destacar, em especial, os avanços tecnológicos que propiciaram a origem dos hipertextos e suas implicações sociais.

\section{DO PAPIRO À RODA DE LEITURA DE AGOSTINO RAMELLI}

Por volta de 3000 a.C., na Mesopotâmia, começaram a surgir formas de escrita utilizando ideogramas e fonemas. Também nesse período, no Egito, eram usados papiros e tintas rudimentares para representação de signos na comunicação escrita. Em diversas regiões agrícolas, durante a Antigüidade, o uso da escrita era relacionado com a contabilidade e o inventário dos templos. Com o surgimento dos primeiros Estados, a escrita servia para a gestão dos grandes domínios agrícolas e para a organização da lavoura e dos impostos. Ao longo dos séculos seguintes, surgiram o alfabeto norte-semítico (Ásia Ocidental, 1700-1500 a.C.), as escritas cuneiforme (Síria, 1400 a.C.) e aramaica (Oriente-próximo, 1000 a.C.) e o alfabeto grego (Grécia, 1000-900 a.C.). As inscrições ainda eram feitas sobre cerâmica e outros materiais, como cera, argila, peles de animais e papiros.

No século III a.C., foi criada a Biblioteca do Museu de Alexandria, a qual tinha como ambição reunir, em um só local, todo o conhecimento do mundo. Surgiram, então, o pergaminho, como outra opção de suporte, e o livro, como reunião de vários pergaminhos ou papiros.

Estima-se que no século IX d.C. começaram a ser escritos os contos árabes Les Mille et Une Nuits ${ }^{4}$, reunidos e traduzidos para a cultura ocidental por Antoine Galland no século XVIII. Essa obra compõe-se de 12 volumes e apresenta um encadeamento contínuo de histórias, isto é, uma história contém outra história, que por sua vez contém outra e assim por diante. Podese dizer que foi uma das primeiras obras a utilizar, de forma consistente, links* em um mesmo documento.

\section{O papel, introduzido no mundo ociden-}

\footnotetext{
* Ligações ou conexões feitas entre nós em um hipertexto. Os nós podem ser trechos, palavras, figuras, imagens ou sons no mesmo documento ou em outro documento hipertexto.
}

FIGURA 2

\section{Roda de leitura de Ramelli ${ }^{5}$}

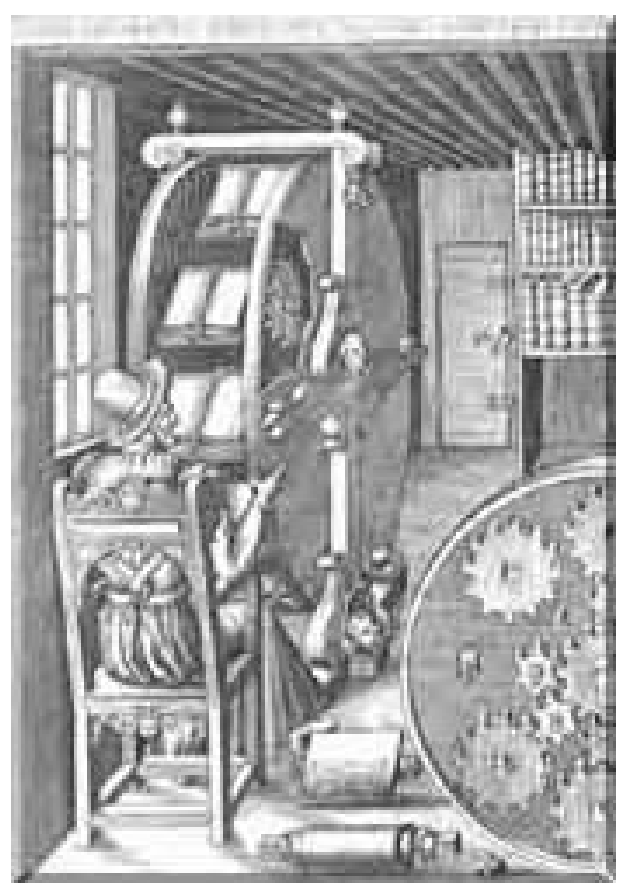

tal em meados do século XII, difundiuse na Europa entre os séculos XIII e $X V$. Em meados do século XV, Gutenberg inventou a imprensa e a tipografia*. A Bíblia de Gutenberg é considerada a primeira publicação impressa. Passamos da era dos manuscritos para a era do papel impresso. A comunicação escrita e o modo de transmissão dos textos sofreram profundas mudanças com a imprensa. A quantidade de livros e cópias produzidos aumentou significativamente, e o leitor passou a ter maior acesso a teorias e conhecimentos, antes restritos aos mestres encarregados de interpretar os manuscritos e repassar seu conteúdo aos discípulos. A leitura e a interpretação adquiriram um caráter mais individualizado, e as obras começaram a incluir representações gráficas mais precisas, tais como tabelas, desenhos, mapas etc.

O livro moderno passou a apresentar uma interface padronizada entre o conteúdo da obra e o leitor, com a incorporação de inventos anteriores à tipografia e o aparecimento evolutivo de vários elementos que conhecemos hoje em dia, tais como paginação, sumários, citações, capítulos, títulos, resu-

mos, erratas, esquemas, diagramas, índices, palavras-chave, bibliografias, glossários etc. Todos esses elementos classificatórios e inter-relacionamentos lógicos são tão corriqueiros para nós que mal notamos sua existência. Porém, na época em que foram inventados, possibilitaram uma interação entre o texto e o leitor completamente diferente daquela que ocorria com os manuscritos. Com esses elementos foi oferecida ao leitor a possibilidade de avaliar o conteúdo da obra de forma rápida e acessar partes do livro que mais the interessavam, de modo seletivo e não-linear. Por meio das notas de rodapé e das referências bibliográficas, o leitor passou a ter conhecimento de outros livros que tratavam do mesmo assunto. Essa nova forma de interação com o conteúdo da obra já mostrava uma certa tendência à não-linearidade.

Os primórdios do hipertexto podem ser associados a uma idéia de Agostino Ramelli cuja proposta era permitir a consulta simultânea de vários livros. A "roda de leitura" foi descrita na obra $L e$ diverse et artificiose machine del Capitano Agostino Ramelli (Paris, 1588):

\footnotetext{
* Impressão com tipos, ou caracteres, remo-

* Impressão com tipos, ou caracteres, remo-
víveis, reutilizáveis e feitos de metal.
} 
"Esta é uma máquina bonita e engenhosa, muito útil e conveniente para qualquer pessoa que tenha prazer em estudar. ...Com esta máquina um homem pode ver e percorrer através de um grande número de livros sem sair do lugar. Esta roda é feita da maneira mostrada, isto é, é construída de tal forma que, quando os livros estão em seus leitoris* ${ }^{*}$ nunca caem ou saem do local em que se encontram, mesmo que a roda gire uma volta completa" (citado em Tolva ${ }^{5}$ ).

Segundo Tolva, esse aparato de leitura não foi implementado por Ramelli. Porém, apesar de haver poucas informações sobre sua construção, existe uma roda de leitura moderna em exposição em Veneza ${ }^{5}$.

No século XVIII, surgiram dois modos de organização da informação em bibliotecas: um deles usava fichas catalográficas, classificadas em ordem alfabética (formadas a partir dos títulos e sumários dos livros) e o outro utilizava índices gerais em árvore (formados a partir de árvores do conhecimento). Ambos tinham como objetivo facilitar o acesso e a busca de informações. Essa biblioteca moderna muito se assemelhava às bibliotecas atuais, apesar de as linguagens documentárias ** mais comuns hoje (Dewey e CDU***) só terem aparecido, respectivamente, no final do século XIX e no início do século $X X$.

FIGURA 3

\section{Roda de leitura moderna ${ }^{5}$}

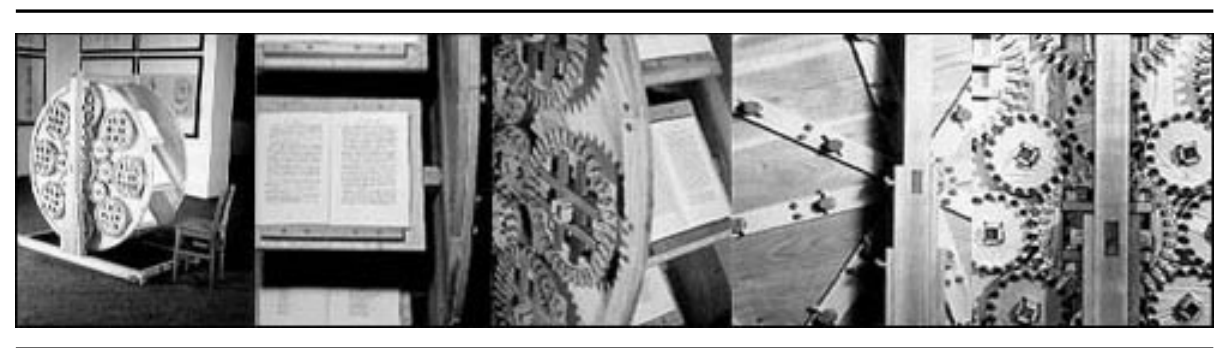

\section{OS AVANÇOS TECNOLÓGICOS NA ERA DA ELETRICIDADE}

A partir do século XIX, muitos foram os avanços tecnológicos no ramo da eletricidade. Vários inventos começaram a influenciar a forma de comunicação da sociedade. Em 1837, o alfabeto foi digitalizado no código Morse e, nos anos subseqüentes, ainda no século XIX, foram inventados o daguerreótipo* , o telégrafo, a máquina de escrever, o fonógrafo** , o telefone e o rádio. Em 1890, nasceu a mecanografia, com o cartão perfurado de Hermann Hollerith.

No início do século $X X$, surgiram outros dispositivos relacionados, de alguma maneira, com a comunicação: o cinema falado, a televisão, o gravador, a caneta esferográfica, a fotocopiadora e os primeiros computadores ${ }^{* *}$. Com essa evolução apareceram também novos suportes : fotossensíveis (filme, microfilme, fotografia e microficha), mecânicos (disco de vinil) e magnéticos (filme polímero recoberto por óxido de ferro ou cromo).

\footnotetext{
* Espécie de estante em plano inclinado, também denominada atril, onde se põe papel ou livro aberto para se ler comodamente.

** Listas de termos de indexação destinadas a descrever e organizar o conteúdo dos documentos.

*** Classificação Decimal Universal.
}

\footnotetext{
* Aparelho primitivo de fotografia.

** Antigo aparelho destinado a reproduzir sons gravados em cilindros ou discos metálicos.

*** Equipamentos utilizados, na época, para cálculos científicos em aplicações militares.
}

\section{DO MEMEX À INTERNET*}

\section{As primeiras idéias de hipertexto e outros avanços tecnológicos contemporâneos}

Em 1945, Vannevar Bush publicou, na revista americana Atlantic Monthly, o artigo "As we may think", onde descreve uma máquina, chamada Memex, capaz de propiciar leitura e escrita nãolineares e armazenar uma biblioteca multimídia** de documentos. Segundo Bush, a mente humana não funciona de forma linear, e sim por associação. Barreto cita Bush, quando destaca que o homem "não está mais preso a uma estrutura linear da informação, que passa a ser associativa em condições de um hipertexto"3. Bush segue dizendo, ainda em seu artigo histórico, que, apesar de ser muito difícil replicar o processo mental artificialmente, os homens devem certamente ser capazes de adquirir algum conhecimento a partir desse processo ${ }^{6}$.

\footnotetext{
* Termo derivado da palavra inglesa internetworking, que significa interconexão de redes. A Internet, na verdade, é composta por uma infra-estrutura computacional e de telecomunicações que propicia a transferência de informações por redes espalhadas por diversos países.

** Termo utilizado para designar aquilo que emprega mais de um tipo de suporte ou veículo de comunicação. Para Lévy ${ }^{9}$, muitas vezes esse termo é usado erroneamente para designar aquilo que emprega diversas formas de representação (textos, imagens, sons etc.) capazes de estimular diferentes modalidades sensoriais (visão, audição, tato e sensações proprioceptivas). Para esses casos, sugere o termo multimodal.
} 
Bush descreveu o Memex como um dispositivo mecanizado em que uma pessoa guardaria todos os seus livros, fotos, jornais, revistas e correspondências e poderia consultá-los de forma rápida e flexível, como se fosse uma extensão de sua memória.

A figura 4 mostra como seria o Memex, isto é, uma mesa com telas translúcidas, teclado, botões, alavancas e mecanismos de armazenamento, gravação e projeção baseados no uso de microfilmes. O processo de ligação entre dois itens seria feito por indexação associativa, em que um item poderia selecionar imediata e automaticamente um outro item para ser lido. Bush acrescenta ainda que, ao ligar vários itens, "é exatamente como se os itens físicos tivessem sido reunidos para formar um livro. É mais que isso, já que qualquer item pode ser ligado a inúmeras trilhas"6.

O Memex, portanto, permitiria o acesso rápido e não-linear a diversas unidades individuais de informação multimídia relacionadas por meio de ligações. Para Shneiderman e Kearsley, essa idéia de Bush trata do elemento mais importante do hipertexto: os links entre documentos ${ }^{7}$.

Essa idéia, no entanto, ficou "adormecida" por quase 20 anos. Para Vilan, "o caminho seguido pela tecnologia da informática separou-se cada vez mais do Memex, à medida que a arquitetura baseada nos postulados de Von Neuman obrigava a informação a organizarse de forma seqüencial, o que não nos surpreende em uma civilização em que o meio básico de comunicação é linear: a escrita (manual ou impressa) ${ }^{8}$.

Na década de 50, foram inventados o rádio a transistor e o circuito integrado. No início dos anos 60, as fitas magnéticas, inventadas em 1956, começaram a ser usadas nos computadores e foi criado o satélite de telecomunicações.

Em 1963, Douglas Engelbart escreveu

\section{FIGURA 4}

\section{Memex de Bush ${ }^{5}$}

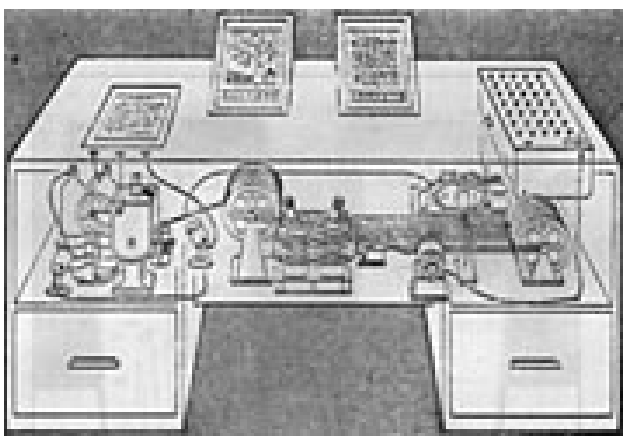

o artigo "A conceptual framework", no qual afirma que o computador poderia "aumentar" o pensamento humano. Em 1965, Engelbart inventou o mouse e Theodore Nelson criou o termo "hipertexto" no seu projeto Xanadu, cuja proposta era implementar uma rede de publicações eletrônica, instantânea e universal - um verdadeiro sistema hipertexto, um universo documental. $\mathrm{O}$ termo hipertexto, no conceito de Nelson, estava relacionado à idéia de leitura/escrita não-linear em sistemas informatizados. Durante suas pesquisas, Nelson descreveu muitas das idéias implantadas nos sistemas hipertexto atuais.

Em 1968, foi apresentado ao mercado o sistema de editoração de texto Augment, desenvolvido pelo Stanford Research Institute, sob a direção de Engelbart. Finalmente, foram colocadas em prática as idéias de Bush e Nelson. O Augment implementava links entre diferentes arquivos, filtros e múltiplas janelas controladas pelo usuário. Os pontos fortes desse sistema eram as inúmeras facilidades que propiciavam o trabalho colaborativo e uma melhor interface entre o usuário e o computador. Dentre os mecanismos de colaboração implementados nesse sistema, podemos citar: mensagens eletrônicas, teleconferência, compartilhamento e arquivamento de mensagens. Para Shneiderman e Kearsley, a demonstração do Augment, feita por Engelbart na Spring Joint Computer Conference, em 1968, foi a "pedra fundamental da história do hipertexto"".

Ainda no final dessa década, foi criada

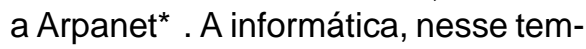

po, era utilizada apenas por grandes corporações, instituições governamentais ou centros de pesquisa, já que servia basicamente para cálculos de maior complexidade, processamento de grandes volumes de dados ou atividades de pesquisa científica. Nesse período, a Brown University, liderada por Andries van Dam, desenvolveu pesquisas sobre sistemas hipertexto, estações de trabalho, processamento de textos, computação gráfica e desenvolvimento de software.

Nos anos 70, a IBM inventou o disquete (como substituto da fita magnética), o qual se tornou um dos suportes mais difundidos na microinformática. Com a comercialização do chip eletrônico, a informática tomou outro rumo e se expandiu na indústria, com a automação industrial e a robótica, e no setor de serviços, com a automação bancária. Com relação à pesquisa sobre hipertextos, iniciou-se, em 1972, na Carnegie Mellon University, o desenvolvimento de um sistema hipertexto distribuído (ZOG, mais tarde chamado de KMS - Knowledge Management System), onde não havia uma separação rígida entre autores e leitores, de forma que as alterações feitas por cada usuário eram lidas por todos os outros.

No final da década de 70, Apple e IBM lançaram seus computadores pessoais. A informática expandiu seu raio de

\footnotetext{
* Rede precursora da Internet, implementada pelo Departamento de Defesa Americano com objetivo de que técnicos e cientistas envolvidos com projetos militares nos EUA pudessem compartilhar computadores e informações.
} 
ação, dos centros de processamento de dados para as mesas dos escritórios. Surgiram o primeiro videodisco hipermídia* Aspen Movie Map, desenvolvido por Andy Lippman do MIT Architecture Machine Group, e o software de processamento de textos Wordstar.

\section{OS AVANÇOS DA DÉCADA DE 80}

Ao longo dos anos 80, apareceram o videotexto, a rede francesa Minitel, a fibra ótica, a primeira tela sensível ao toque, o processador de texto do Macintosh da Apple, com Wyiwyg**, memórias óticas, scanners ${ }^{* \star *}$, videodiscos, cd-roms ${ }^{* * *}$, TCP/IP (Transport Control Protocol / Internet Protocol protocolo de comunicação ${ }^{\star * * * *}$ ) e a Internet $^{\star * * * * *}$. Esses avanços, o aumento da capacidade de armazenamento e processamento de dados dos computadores e o surgimento de interfaces gráficas mais amigáveis (com menus, janelas e ícones acionados por um "click" do mouse) permitiram que a informática passasse a fazer parte do cotidiano das pessoas comuns e os sistemas hipertexto se tornassem comercialmente viáveis.

Vários projetos de sistemas hipertexto foram desenvolvidos nessa década, tais como:

\footnotetext{
* Tipo de hipertexto onde há links entre textos, sons e imagens.

** What You See Is What You Get - é impresso exatamente o que se vê na tela do computador.

*** Equipamentos utilizados na digitalização de documentos impressos.

**** Abreviatura de Compact Disc - Read Only Memory - discos compactos a laser, semeIhantes aos CDs de áudio, usados para armazenamento de dados e programas de computador.

***** Conjunto de regras e comandos estabelecido entre os componentes de uma rede de computadores, que permite a comunicação entre eles.

****** Nessa década, a utilização da Internet se expandiu no meio acadêmico.
}

- Guide - University of Canterbury - desenvolvido por Peter Brown, foi o primeiro sistema hipertexto para computadores pessoais;

- TIES (The Interactive Encyclopedia System, posteriormente chamado Hyperties) - University of Maryland desenvolvido por Ben Shneiderman e usado em inúmeras aplicações, tais como exposições de museus, arqueologia, fotografia, manuais on-line etc.;

- KMS (sucessor do ZOG) - comercializado pela Knowledge Systems, Inc. para estações de trabalho Sun e Apollo;

- Notecards - Xerox Palo Alto Research Center - desenvolvido por Frank Halasz, Randy Trigg e Tom Moran, para suportar tarefas de leitura, categorização, interpretação e escrita de material técnico;

- Intermedia - Brown University - sistema para documentos multimídia desenvolvido pelo Institute for Research and Scholarship (Iris). Nesse sistema, os links pertenciam a webs (redes), de tal forma que, para visualizar um documento, o usuário devia selecionar uma web específica. Os links eram, assim, dependentes de contexto;

-WE (Writing Environment) - University of North Carolina - projeto baseado em modelo de processos cognitivos envolvidos na autoria de textos, cujo objetivo era suportar todas as fases do processo de escrita de textos (conteúdo e estrutura);

- Hypercard - Apple Computer - desenvolvido por Bill Atkinson, para computadores Macintosh.

Em 1983, foi defendida, por Randall Trigg, na University of Maryland, a primeira tese de PhD sobre hipertexto, e, na Carolina do Norte, em 1987, aconteceu o primeiro grande workshop sobre hipertexto - Hypertext ' 87.

A Web, isto é, a World Wide Web* , foi proposta em 1989 por Tim Berners-Lee. Essa rede global nada mais é do que uma imensa biblioteca multimídia, ou seja, um conjunto de documentos hipertexto, com informações digitalizadas de textos, sons e imagens, conectados entre si e espalhados por computadores do mundo inteiro.

\section{OS AVANÇOS DA DÉCADA DE 90}

No início dessa década, foram desenvolvidos a linguagem $\mathrm{HTML}^{* *}$ (subconjunto da SGML ${ }^{* * *}$ ) e o protocolo de comunicação HTTP (HyperText Transfer Protocol), os quais possibilitaram a produção e a disseminação de documentos hipertexto pela rede mundial de computadores - a Internet. Nesse período, a Internet deixou o meio acadêmico e ganhou adeptos das mais diferentes nacionalidades e profissões. Desde então, o número de servidores $^{* * * *}$ Internet e de novos usuários vem aumentando exponencialmente a cada ano.

Os sistemas hipertexto começaram a ser efetivamente utilizados, principalmente nas áreas de educação, comunicação e organização de dados. Em 1993, a venda de enciclopédias hipermídia ultrapassou seus equivalentes impressos. Algumas instituições governamentais passaram também a utilizar a Internet como dispositivo de divulgação de informações, estruturadas em hipertextos. Nessa época, a baixa velocidade dos meios de telecomunicação (por onde trafegam os dados) e a pouca interatividade das ferramentas disponíveis dificultavam o acesso às informações na Web.

Para melhorar a interface homem-máquina, tornando-a mais amigável e intuitiva, foram desenvolvidos vários pro-

\footnotetext{
* Sistema ou serviço de recuperação de informações por meio da Internet, também conhecido pela sigla WWW.

** Abreviatura de HyperText Markup Language, linguagem composta por um conjunto de comandos de formatação e utilizada na criação de documentos hipertexto, visualizados nas páginas WWW.

*** Abreviatura de Standard Generalized Markup Language, sistema padronizado de organização de documentos, desenvolvido pela International Organization for Standards (ISO).

**** Nomenclatura dada aos computadores que conectados em uma rede cliente-servidor, fornecem informações ou prestam serviços aos clientes (computadores pessoais ou estações de trabalho que constituem a interface direta com o usuário).
} 
jetos como o Mosaic e o Netscape. Em 1995, as ações da Netscape Corp. foram transacionadas em Wall Street, causando alvoroço no mercado. Várias empresas começaram a anunciar e vender produtos pela Web. O comércio chega à Internet - é a era do comércio eletrônico.

Os avanços apresentados na área de telecomunicações, nos anos subseqüentes, e essa interface mais amigável fizeram com que a Internet "explodisse". Dentre outros serviços, a Internet passou a oferecer correio eletrônico, transferência de arquivos, listas de distribuição, grupos de usuários e a web propriamente dita (WWW), com seus serviços de busca de informações e sua infinidade de hipertextos - textos, sons e imagens em uma verdadeira rede de informações. Para Lévy, "as tecnologias digitais surgiram, então, como a infra-estrutura do ciberespaço* , novo espaço de comunicação, de sociabilidade, de organização e de transação, mas também novo mercado da informação e de conhecimentos"'.

\section{ESTÁGIO ATUAL DA PESQUISA CIENTÍFICA SOBRE HIPERTEXTOS}

Como acontece anualmente, desde 1987, a conferência Hypertext '99 (ocorrida em fevereiro deste ano) apresentou os últimos resultados de pesquisas e projetos sobre hipertexto. Este ano, em especial, foi dada ênfase à hipermídia e ao estabelecimento de padrões para o desenvolvimento de hipertextos. Dentre os diversos temas abordados, podemos destacar:

- padrões, tais como XML, SMIL, XLink e WebDAV* ;

- métodos de avaliação, desenvolvimento e design de hipertextos e hipermídias;

\footnotetext{
* Novo meio de comunicação que surge da interconexão mundial dos computadores. Segundo Lévy [09], esse termo foi inventado em 1984 por William Gibson no romance de ficção científica Neuromante, onde é definido como sendo o universo das redes digitais palco de conflitos mundiais e uma nova fronteira econômica e cultural.
}

- Open Hypermedia Systems (OHS) ${ }^{\star *}$;

- hipermídia (interfaces, novas tecnologias de armazenamento, design utilizando arquitetura orientada a objetos, espaços tridimensionais etc.);

• aplicações para a Internet;

- estudos de ergonomia e psicologia cognitiva.

\section{Efeitos sociais de uma nova tecnologia}

A primeira idéia que nos vem à mente quando se fala em hipertexto é a nãolinearidade. Porém, é bom destacar que, antes da informática, já existiam elementos que possibilitavam a leitura não-linear, como os sumários, as referências bibliográficas e as notas de rodapé. A tecnologia da informação, entretanto, proporcionou maior velocidade de acesso, um volume infinitamente maior de documentos disponíveis à sociedade, e associações, em uma mesma mídia, de textos, imagens e sons, como presenciamos hoje na Internet.

Sem dúvida, com o hipertexto, criouse nova maneira de leitura e escrita de documentos, em que os papéis desempenhados por autores e leitores se confundem. O autor, ao elaborar um hipertexto, na verdade, constrói "uma matriz de textos potenciais", os quais são alinhavados, combinados entre si, pelo leitor, como uma leitura particular dentre as inúmeras alternativas possíveis. O leitor, portanto, participa ativamente da redação e edição do documento que lê, podendo, até mesmo, traçar caminhos nunca antes imaginados pelo autor, conectando uma infinidade de documentos, como se estivesse criando um novo documento hipertexto a partir dessas associações. O conhecimento não precisa mais estar preso a uma página impressa: todos os tipos de acessos cruzados entre documentos são autorizados. Na opinião de

\footnotetext{
* Padrões ou linguagens padronizadas para elaboração de hipertextos.

** Tema de pesquisa que trata da integração da funcionalidade da hipermídia às ferramentas existentes no ambiente computacional, enfocando as áreas de biblioteca virtual, suporte computacional a empresas de engenharia, desenvolvimento de software e educação.
}

Lévy, "com o hipertexto, toda leitura é uma escrita potencial"s.

Do ponto de vista da autoria, também ocorreram mudanças. O processo de criação de hipertextos passa, quase que necessariamente, pela leitura de outros documentos hipertexto disponíveis, os quais poderão ser associados ao hipertexto em elaboração. O autor, portanto, ao estruturar seu documento, lê, avalia e estabelece links a outros documentos que possam contribuir para o entendimento de seu ponto de vista ou servir como bibliografia sugerida sobre o assunto abordado. Com a incorporação de sons e imagens aos textos, em uma rede de nós interligados, certamente a escrita hipertextual requer habilidades adicionais de seus autores. Isso pode levar a uma certa reação, pois é comum condenarmos aquilo que nos parece estranho ou diferente do padrão que nos foi transmitido através dos milhares de anos desde a invenção da escrita.

Outro aspecto a ser analisado é a interatividade proporcionada pelo hipertexto. Nos meios de comunicação de massa, como a imprensa, o rádio, a televisão e o cinema, a difusão se dá de forma unilateral, impondo somente uma visão da realidade (dos grupos proprietários das mídias), sem abrir espaço para resposta, crítica ou confronto de idéias antagônicas. No caso dos documentos hipertexto acessíveis on-line na Internet, por exemplo, é possível afirmar que o fluxo informacional pode ser reorientado ou interrompido em tempo real e que existe um verdadeiro diálogo entre os participantes da comunicação. Os hipertextos são frutos da leitura/escrita de uma comunidade, pois cada pessoa estabelece um novo texto a cada link percorrido, podendo, inclusive, no caso de hipertextos abertos, acrescentar seus próprios links, observações e figuras ao hipertexto original. A interatividade dos hipertextos permite, portanto, a concepção de obras coletivas, nas quais os conhecimentos de várias pessoas podem ser concatenados entre si de forma mais ágil.

Há também a possibilidade, proporcionada pela Internet, de qualquer pessoa expor seus pontos de vista, sem restrições, em documentos hipertexto por 
ela elaborados e colocados à disposição de qualquer um que tenha acesso à rede. É claro que a Internet, independentemente de sua hipertextualidade, acarreta outros inúmeros impactos sociais. Porém, nos ateremos, aqui, apenas às implicações sociais relacionadas aos hipertextos.

A interatividade e o compartilhamento de informações sob a forma de textos, sons e imagens, proporcionados pelos hipertextos, promovem o desenvolvimento de novas relações com as fontes do saber e são, indubitavelmente, novos aspectos a serem considerados nos métodos educacionais de construção do conhecimento. Os sistemas hipertexto permitem um novo tipo de aprendizagem: a aprendizagem coletiva, cooperativa e interativa. Estudantes e professores partilham de uma mesma base de conhecimentos inicial que se amplia à medida que são acrescidos novos links (com observações pessoais ou sugestões de novas referências bibliográficas, por exemplo), novos textos, imagens e sons. $\mathrm{O}$ envolvimento pessoal e interativo do estudante é, reconhecidamente, fundamental no processo de aprendizagem. Quanto mais participa da aquisição de conhecimento, questionando-se e respondendo a suas próprias questões, mais facilmente entende e assimila o que aprende. $O$ hipertexto e a multimídia favorecem, portanto, a participação ativa e exploratória do estudante, ao interagir com a não-linearidade e os diversos estímulos sensoriais desse ambiente.

O hipertexto provê ainda outras vantagens educacionais. Uma delas é o acesso imediato, e praticamente ilimitado a enormes volumes de informação, de forma direta (em contraposição ao acesso seqüencial do texto tradicional). O estudante vai direto ao assunto que lhe interessa. A estrutura lógica arbitrada pelo autor, em documentos seqüenciais, pode ser contraproducente no processo de aprendizagem de algumas pessoas. Com o hipertexto, o estudante tem a liberdade de estruturar o documento da forma que mais lhe convém, melhorando e acelerando sua compreensão do tema em estudo. O hipertexto, como dispositivo didático, provê um ambiente propício à
FIGURA 5

\section{Vídeos em tempo real ${ }^{10}$}

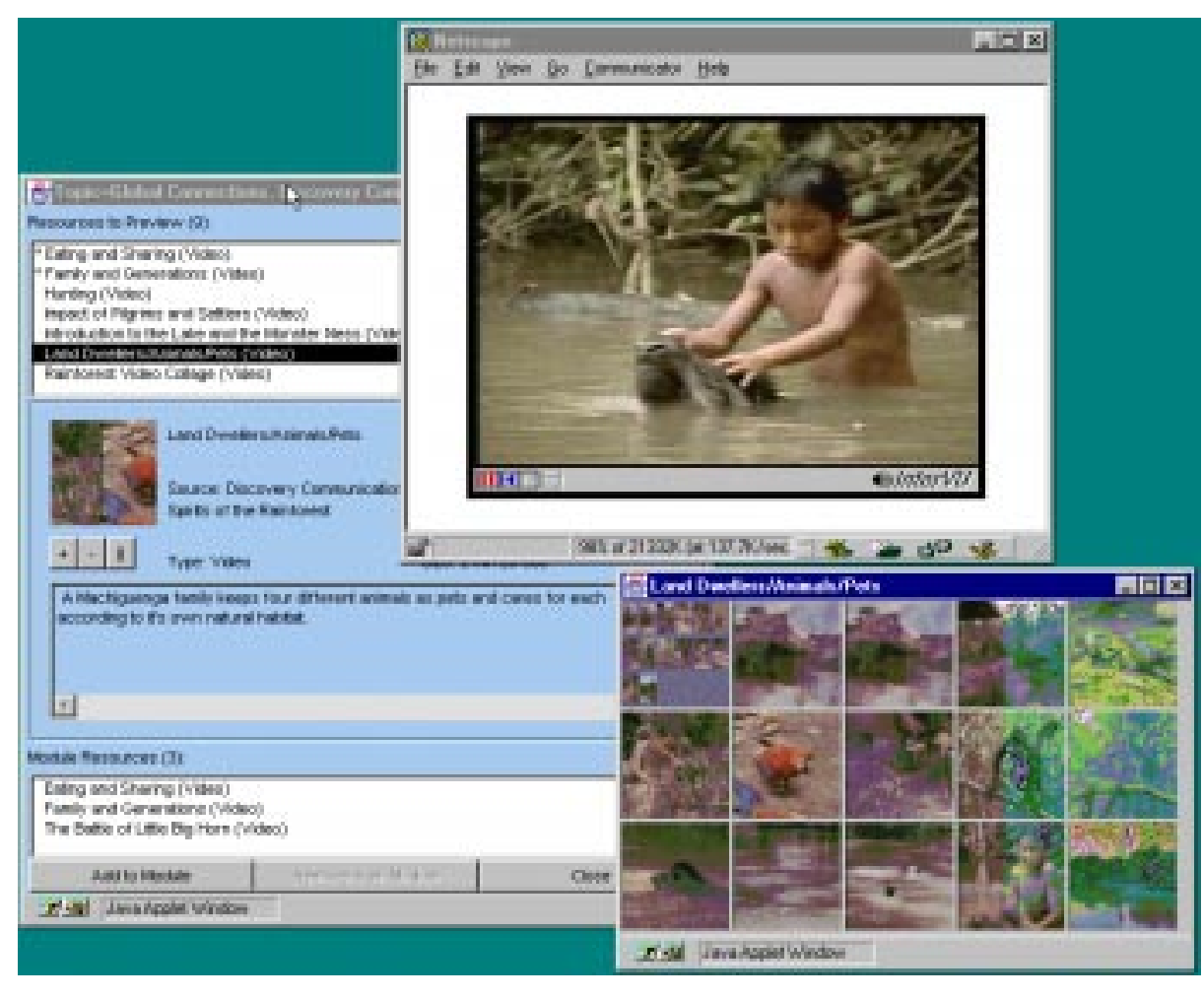

exploração, em que o aluno desenvolve seu próprio estilo cognitivo. Outra vantagem, como uma alternativa à escolha livre dos links a serem percorridos, é a oportunidade de tours* guiados, de acordo, por exemplo, com o grau de conhecimento do estudante, com o objetivo de tornar-Ihe mais compreensível a informação.

Além disso, com o uso das redes de telecomunicação e dos suportes multimídia interativos, o hipertexto permite a implementação de bibliotecas virtuais* e ensino à distância, o qual vem se integrando cada vez mais aos métodos tradicionais de ensino presencial. Dessa forma, utilizando a informática, a multimídia e os sistemas hiper-

* Trilhas ou caminhos predefinidos pelo autor, em um documento hipertexto. texto abertos, como suportes pedagógicos, professores e estudantes aprendem juntos em uma nova modalidade de ensino.

O hipertexto, como uma nova tecnologia, não tem como objetivo suplantar o livro, na sua forma tradicional. Dependendo do conteúdo e de sua aplicação, a forma hipertextual pode ser mais ou menos adequada que o livro impresso. Por exemplo, dicionários, enciclopédias e manuais de equipamentos se aplicam mais ao formato multimídia e nãolinear dos hipertextos, enquanto os romances literários são mais adequados ao formato impresso.

Entretanto, o hipertexto não apresenta apenas vantagens. Várias pesquisas têm sido desenvolvidas com o objetivo de minimizar suas desvantagens, como, por exemplo, a desorientação do usuário em meio a tantas informações. As ferramentas de busca, os menus e os mapas de conteúdo, já implementados em sistemas hipertexto comerciais e na Internet, são exem-

* Sistemas macroliterários, em bases computadorizadas, normalmente remotas, capazes de suportar grandes conjuntos bibliográficos ou documentais, oferecendo acesso on-line aos usuários da rede. 
plos de produtos gerados por essas pesquisas.

Os críticos mais vorazes das novas tecnologias tendem a condená-las, temendo uma completa substituição das tecnologias anteriores capaz de provocar transformações sociais negativas. Em nosso entendimento, essa posição é exagerada. Ao contrário, podemos afirmar que raramente uma nova forma de comunicação suplanta completamente as anteriores, e a história nos tem provado isso.

Com o advento da escrita, as pessoas não deixaram de se comunicar oralmente. A imprensa não fez com que as pessoas deixassem de escrever com as próprias mãos. A fotografia não substituiu a pintura, assim como a televisão não substituiu o teatro ou o rádio. As videolocadoras e as TVs a cabo não provocaram a falência dos cinemas. Certamente, o surgimento de cada uma dessas tecnologias citadas modificou, de alguma maneira, a tecnologia anterior, porém não foi capaz de substituíla por completo. Cada tecnologia acaba encontrando seu nicho e seu público-alvo, sendo adotada nos casos e contextos em que, dentre todas as tecnologias existentes, ela é a mais adequada. O mesmo acontecerá com os livros e os hipertextos.

Podemos generalizar dizendo que as tecnologias, por si mesmas, não determinam nada; não são boas, nem más. Essa visão maniqueísta de identificar as novas tecnologias como causas do mal contemporâneo, compartiIhada por alguns autores, é muito simplista e tendenciosa. O confronto homem-máquina e a Internet, com sua rede infinita de hipertextos, têm sido alvo de críticas desse gênero.

Em oposição a esse pensamento, Lévy afirma que "nenhuma técnica tem uma significação intrínseca, um ser estável, mas apenas o sentido que é dado a ela sucessiva e simultaneamente por múltiplas coalizões sociais. ...A significação e o papel de uma configuração técnica em um momento dado não podem ser separados do projeto que move esta configuração, ou talvez dos projetos rivais que a disputam e puxamna em todos os sentidos"1. A tecnologia em si mesma não é digna de condenação ou exaltação. O uso que se faz dela é que pode ser vil ou nobre.

Eventualmente, a inovação tecnológica pode gerar grupos de excluídos e provocar o desaparecimento de métodos antigos, formas de pensamento ou conhecimento não mais considerados adequados para a época. Ninguém discute, por exemplo, a importância do telefone para a comunicação social. Entretanto, é enorme a quantidade de pessoas no mundo que não têm acesso a uma linha telefônica, constituindo, assim, seu grupo de excluídos. A própria escrita tem sua parcela de excluídos. A exclusão não pode nos privar de vislumbrar formas de uso das novas tecnologias que contribuam para o desenvolvimento social como um todo.

\section{CONCLUSÃO}

No início dos tempos da comunicação, havia uma pluralidade de sociedades, de cultura oral, vivendo fechadas em si mesmas. Cada tribo tinha sua própria linguagem e partilhava um contexto único. O conhecimento, limitado às lembranças dos mais velhos, era repassado, de geração a geração, apenas aos membros daquela comunidade.

Com a escrita e, em seguida, com a imprensa, abriu-se uma nova perspectiva, universal, de comunicação e difusão de conhecimentos. Os "mais instruídos", autores dos livros, repassavam sua visão particular do mundo, influenciando a todos e difundindo suas idéias a quem tivesse a oportunidade de ler suas obras.

$\mathrm{Na}$ fase atual de evolução da comunicação, com a cibercultura* ${ }^{*}$ conseguimos atingir a universalidade e a diversidade de comunidades, com pontos de vista por vezes desiguais e conflitantes. Com a virtualização e a globalização da sociedade, o processo de produção da informação e do conhecimento deixou de ser hierárquico para se tornar horizontal, descentralizado e interativo. Neste período pós-gutenber- guiano, como afirma Miranda, "será possível imaginar buscas eletrônicas em imensos e variados estoques textuais, em escala planetária com as facilidades do hipertexto para passar de uma fonte a outra no aprofundamento do conhecimento"11.

O hipertexto se insere nesse contexto da cibercultura, como uma de suas novas interfaces de comunicação. $\mathrm{Na}$ verdade, o hipertexto resgata e modifica antigas interfaces da escrita, como a segmentação em módulos (capítulos e seções), o acesso seletivo e nãolinear ao texto (índices e sumários), as conexões a outros documentos (notas de rodapé e referências bibliográficas), implementadas com novas tecnologias. Essa nova maneira de escrever pode ser usada para organizar e divulgar os conhecimentos sobre uma determinada área do saber, sendo especialmente útil nas áreas de gestão de informações, comunicação e educação.

A sociedade, ao aprender a lidar com os hipertextos, pode aproveitar todo seu potencial cognitivo, interativo e multimodal, como recurso pedagógico, meio de comunicação e de divulgação de conhecimento na era da informática.

Vale lembrar que toda inovação tecnológica gera fenômenos educacionais, culturais e sociais. Entretanto, ela, por si só, não é capaz de resolver, de uma hora para outra, os problemas econômicos e sociais da era em que foi idealizada. Ela apenas contribui para o despertar de uma nova concepção, um novo saber, transformando a capacidade de entendimento das gerações que a vivenciam. Devem surgir iniciativas, essencialmente governamentais, para

\footnotetext{
* Conjunto de técnicas, práticas, atitudes, modos de pensamento e valores que se desenvolveram com o crescimento do ciberespaço ${ }^{9}$.
} 
reduzir o desequilíbrio cultural e social, com intuito de proporcionar, a uma parcela cada vez maior da população, acesso às novas tecnologias, à informação e ao conhecimento. Cabe à sociedade examinar as potencialidades da nova tecnologia, acompanhar sua trajetória e identificar seu nicho, visando à aprendizagem, ao crescimento e ao desenvolvimento humano em sociedade.

\section{Hypertext : historical evolution and social effects}

\section{Abstract \\ In this chronological exposition, the author analyses the improvements in information communication, going through different cultural and technological phases - the writing, the press and the infomation technology. The purpose of this article is to point out the technological improvements that gave rise to hypertexts, and the social effects of this new technology.}

\section{Keywords}

Hypertext; Hypermedia.

\section{REFERÊNCIAS BIBLIOGRÁFICAS}

1. LEVY, Pierre. As tecnologias da inteligência : o futuro do pensamento na era da informática. Rio de Janeiro : Ed. 34, 1993. 208 p. (Coleção TRANS).

2. MASUDA, Yoneji. A sociedade da informação. Rio de Janeiro: Editora Rio, 1980.

3. BARRETO, Aldo. Mudança estrutural no fluxo do conhecimento: a comunicação eletrônica. Ciência da Informação, v. 27, n. 2, p. 122-127. Brasília: IBICT, maio/ ago. 1998.

4. Les Mille et Une Nuits. Contes arabes. Tome I. Traduction d' Antoine Galland. Paris: Booking International, 1996. 320p.

5. TOLVA, John. Hypertext - renaissance : hypertext before computers. [on-line], abr. 1999. [http://www.mindspring.com/ jntolva/ramelli.html].

6. BUSH, Vannevar. As we may think. Atlantic Monthly, n. 1, p.101-108, July 1945 [online], maio 1999. [http://www.ps.unisb.de/ duchier/pub/vbush/vbushall.shtml].

7. SHNEIDERMAN, Ben \& KEARSLEY, Greg. Hypertext hands-on! : an introduction to a new way of organizing and accessing information. Reading, Mass.: AddisonWesley, 1989. $166 \mathrm{p}$.

8. VILAN Fo, Jayme. Hipertexto: visão geral de uma nova tecnologia de informação. Ciência da Informação. v. 23, n. 3, p. 295-308. Brasília: IBICT, set./dez. 1994.

9. LEVY, Pierre. Cibercultura. São Paulo: Editora 34, 1999. 264p. (Coleção TRANS).

10. DING, Wei \& MARCHIONINI, Gary. Overviews and previews for multimedia instructional resources. In: ASIS '98, Pittsburgh, PA, oct. 1998. Proceedings.... [on-line], jun. 1999. [http://www.learn. umd.edu/reports/asis98/].

11. MIRANDA, Antonio. Globalización y sistemas de información: nuevos paradigmas y nuevos desafíos. In: CONFERENCIA REGIONAL POLÍTICAS Y ESTRATEGIAS PARA LA TRANSFORMACIÓN DE LA EDUCACIÓN SUPERIOR EN AMÉRICA LATINA Y EL CARIBE, La Habana, Cuba, nov. 1996. La educación superior en el siglo XXI. Visión de América Latina y el Caribe. Caracas: CRESALC/UNESCO, 1997. p. 1009-1021. (Colección Respuestas).

12. BARGER, Jorn. HyperTerrorist's timeline of hypertext history. March, 1996. [on-line], abr. 1999. [http://www.mcs.net/ jorn/ $\mathrm{html} /$ net/timeline.html]

13. CANALS, Isidre. Introducción al hipertexto como herramienta general de información : concepto, sistemas y problemática. Revista Española de Documentación Científica, v. 13, n. 2, p. 685-709, abr./ jun. 1990.

14. CAPODAGLI, James. Hypertext and hypermedia: conceptual design and the learner. IDE 880, Summer 1989.
15. FAYET-SCRIBE, Sylvie. Chronologie des supports, des dispositifs spatiaux, des outils de repérage de l'information. sept. 1997. [on-line], abr. 1999. [http:// www.info.unicaen.fr/bnum/jelec/Solaris/ d04/4fayet Ointro.html].

16. GROUPEMENTD'INTERET SCIENTIFIQUES Sciences de la cognition: le livre électronique. Nov. 1998. [on-line], maio 1999. [http://www-poleia.lip6.fr/gis.cognition/ somliv.html].

17. JONASSEN, David. Designing structured hypertext and structuring access to hypertext. Educational Technology, v. 28, n. 11, p. 13-16, nov. 1988.

18.

Hypertext principles for text and courseware design. Educational Psychologist, v. 21, n. 4, p. 269-292, 1986

19. MARCHIONINI, Gary. Hypermedia and learning: freedom and chaos. Educational Technology. v. 28, n. 11, p. 8-12, nov. 1988

20. NIELSEN, Jakob. Short History of Hypertext. In: Multimedia and hypertext: the Internet and beyond. AP Professional, 1995. [on-line], abr. 1999. [http://www.sun.com/950523/columns/ alertbox/history.html]

21. SMITH, Craig. The Gutenberg Bible. [on-line], maio 1999. [http://www.osl. state.or.us/csimages/bible/bible.htm].

22. TEIXEIRA, Cenidalva \& SCHIEL, Ulrich. A Internet e seu impacto nos processos de recuperação da informação. Ciência da Informação On-line. [on-line], abr. 1999. [http://www.ibict.br/cionline/ 2619708a.zip]

23. VILCHES, Lorenzo. Globalização comunicativa e efeitos culturais. In: Globalização, mídia e cultura contemporânea. Campo Grande: Letra Livre, 1997.

\section{Cláudia Augusto Dias}

Mestranda em ciência da informação na Universidade de Brasília (UnB). Formada em engenharia elétrica pela Universidade de Brasília. Trabalha como auditora de sistemas no Tribunal de Contas da União (TCU).

e-mail: claudiaad@yawoo.com 